\title{
Effects of the Out-of-pocket Payment Exemption in the Public Health Center on Medical Utilization of the Korean Elderly
}

\author{
Kiryong Nam ', Eunhye Park', Yuhjin Chung ', Chang-yup Kim ${ }^{2,3}$ \\ ${ }^{1}$ Department of Preventive Medicine, Graduate School of Public Health, Seoul National University, Seoul, Korea; ${ }^{2}$ Department of Public Health \\ Science, Graduate School of Public Health, Seoul National University, Seoul, Korea; 'Institute of Health and Environment, Seoul National University, \\ Seoul, Korea
}

Objectives: The distribution of hospitals in Korea is unbalanced in terms of accessibility. Many local public health centers (PHCs) exempt out-of-pocket payments (OOPs) based on local government laws to increase coverage. However, this varies across administrative regions, as many make this exemption for the elderly, while others do not. This study aimed to evaluate the effects of the OOP exemption at local PHCs among elderly individuals.

Methods: This study used online data on Korean national law to gather information on individual local governments' regulations regarding OOP exemptions. Individual-level data were gathered from the 2018 Community Health Survey and regional-level data from public online sources.

Results: The study analyzed 132 regions and 44918 elderly people. A statistical analysis of rate differences and 2-level multiple logistic regression were carried out. The rate difference according to whether elderly individuals resided in areas with the OOP exemption was 1.97\%p (95\% confidence interval [Cl], 1.07 to 2.88) for PHC utilization, $1.37 \% \mathrm{p}(95 \% \mathrm{Cl}, 0.67$ to 2.08 ) for hypertension treatment, and $2.19 \% \mathrm{p}(95 \% \mathrm{Cl}, 0.63$ to 3.74$)$ for diabetes treatment. The regression analysis showed that OOP exemption had an effect on hypertension treatment, with a fixed-effect odds ratio of 1.25 ( $95 \% \mathrm{Cl}, 1.05$ to 1.48$)$.

Conclusions: The OOP exemption at PHCs can affect medical utilization in Korea, especially for hypertension treatment. The OOP exemption should be expanded to improve healthcare utilization in Korea.

Key words: Health expenditures, Primary healthcare, Aged, Local government, Community health centers, Public sector

\section{INTRODUCTION}

Received: July 20, 2020 Accepted: October 6, 2020

Corresponding author: Chang-yup Kim, MD, PhD Department of Public Health Science, Graduate School of Public Health, Seoul National University, 1 Gwanak-ro, Gwanak-gu, Seoul 08826, Korea

E-mail: cykim@snu.ac.kr

This is an Open Access article distributed under the terms of the Creative Commons Attribution Non-Commercial License (https://creativecommons.org/licenses/bync/4.0// which permits unrestricted non-commercial use, distribution, and reproduction in any medium, provided the original work is properly cited.
The function of public health centers (PHCs) in Korea, known as bogeonso, varies depending on the regional administrative division, population density, demographic distribution, and regional context. Unlike regions near Seoul, metropolitan areas, and large cities, PHCs play an important role in primary care in regions with a low population density and a small number of private hospitals. With the recent growth of the elderly population, many local governments have exempted out-of-pocket payments (OOPs), also known as a copayments, for the elderly 
at PHCs through local administrative laws. However, these laws vary from region to region, and there are still many places without the OOP exemption. Evidence of the effects of copayments has been obtained from earlier international studies [1], but in Korea's regional context, with consideration of the magnitude of OOPs and national insurance coverage, the effects of these copayments may be of crucial importance when making public health policy.

After the enactment of the Regional Public Health Act in 1995, each local government has established a local healthcare plan every 4 years and revised related regulations based on these plans. Policy determinants include the number of people in the region, the finances and size of the local council, the characteristics of the head of local government, the voter turnout, and the social welfare budget [2]. After this act was enacted, several local governments implemented policies to reduce the copayments of the elderly at PHCs to meet the demands of the residents, and these policies seem to have spread through the policy diffusion effect [3-5].

The cost of OOPs at PHCs is not high in absolute terms, but many systematic reviews have nonetheless shown that increases in OOPs are associated with decreasing medical utilization and worse health outcomes, both in high-income and low-income countries $[6,7]$.

The utilization of PHCs is positively associated with old age, female sex, low education and income levels, hypertension (HTN), and receiving Basic Livelihood Security Program benefits. PHC utilization is also associated positively with regions that have a high elderly population, a low number of healthcare workers per population, and low financial independence of the local government [8].

No studies have yet summarized the OOP exemption policies provided by local governments or analyzed their associations with medical utilization and health outcomes. Therefore, this study was conducted to evaluate the associations of OOP exemption policies at the municipality level with the utilization of PHCs and the treatment rate of chronic diseases such as HTN and diabetes mellitus (DM).

\section{METHODS}

\section{Research Question}

The PICO format was used to formulate the research question. The population $(\mathrm{P})$ comprised elderly individuals living in local areas where PHCs are the main source of primary care. The in- tervention (I) was the local government policy of OOP exemption. The comparison $(C)$ was elderly individuals living in local areas with no OOP exemption. The outcome (O) was utilization of PHCs and the treatment rate of HTN and DM. The research model is shown in Figure 1.

Potential confounding factors were chosen using the causal theory of directional acyclic graphs [9], and included demographic factors, economic measures, and distribution of medical institutions.

\section{Data Resources and Variables}

Data on OOP exemption policies were gathered from the Korea Ministry of Government Legislation website (with the exclusion of Seoul, Sejong, and 6 metropolitan cities [gwangyeoksi]). Individual data were obtained from the 2018 Community Health Survey, which was conducted by the Korea Centers for Disease Control and Prevention among 228340 respondents. Data on regional-level confounders were gathered from the Korean Statistical Information Service (http://kosis.kr/) and the Public Data Portal (https://www.data.go.kr/).

In total, 44918 survey respondents were analyzed. The inclusion criteria were being 65 years of age or older, and the exclusion criteria were receiving Basic Livelihood Security Program benefits, residing in metropolitan cities, and residing in regions with at least 30 times more other medical facilities than PHCs; the final criterion was chosen to exclude regions where $\mathrm{PHCs}$ play a minimal role in providing primary care.

The dependent variable of medical utilization was analyzed based on the survey question asking whether the respondent had used a PHC in the last ear. HTN treatment was considered adequate if the patient took HTN medication more than 20 days in a month. DM treatment was considered adequate if the patient was taking medication or using insulin.

The main independent variable was OOP exemption at PHCs by local governmental laws, which differ across municipalities. Exemptions not relevant to medical utilization such as free vaccination programs were not included as OOP exemptions. The main focus was on distinguishing whether a person using a PHC for medical treatment needs to pay or not.

The other independent variables were the proportion of the elderly population, the number of PHCs (including health centers, headquarter of public health of the region; health center branches, facilities mainly of community medical care with 1 or 2 doctors; and healthcare centers, facilities mainly of chronic disease management without any doctors), the ratio of oth- 


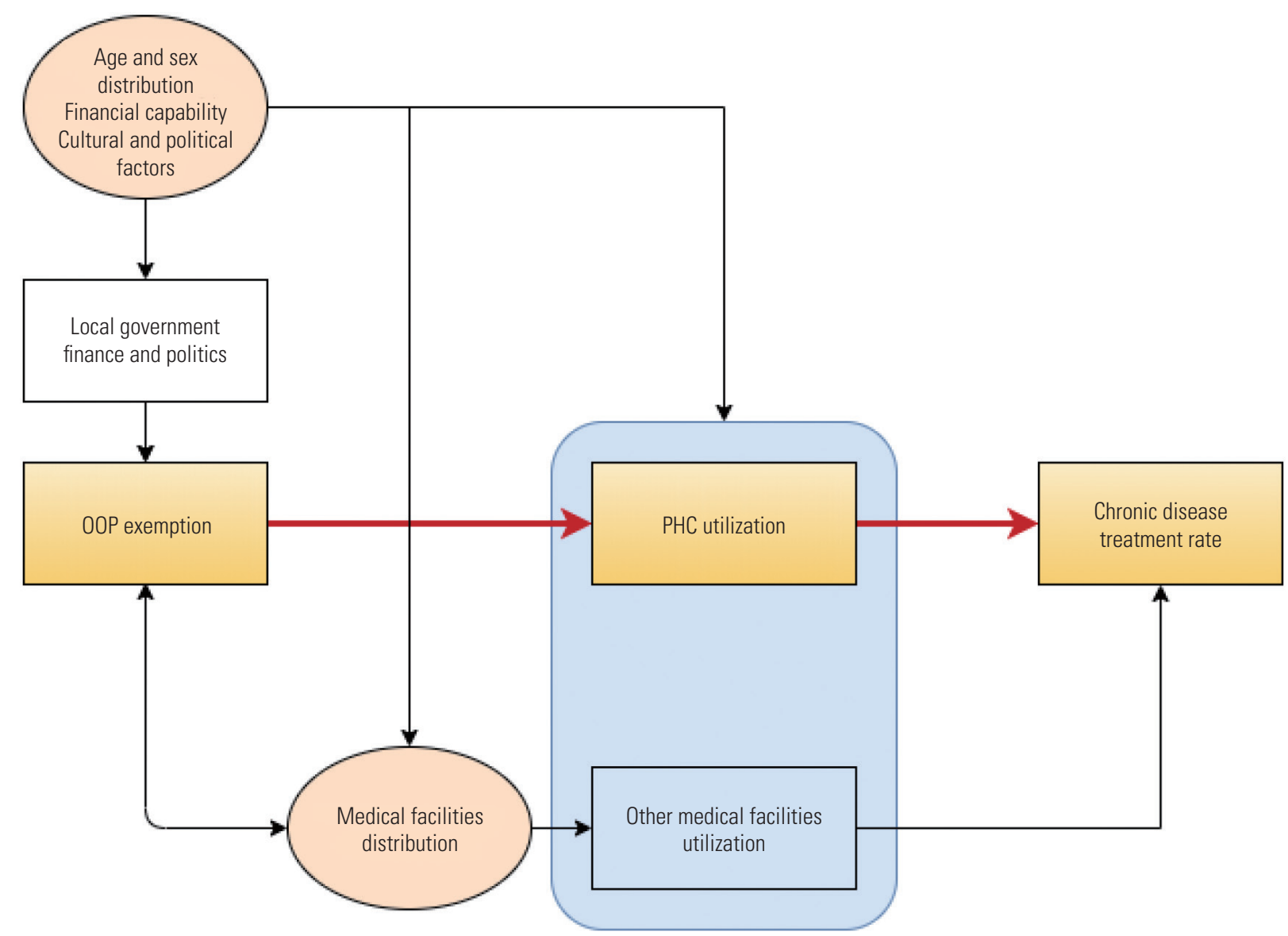

Figure 1. Causal model between out-of-pocket payment (OOP) exemption, public health center (PHC) utilization, treatment rate, and other variables to be considered.

er medical facilities to PHCs at the region level, and sex, age, and household income at the individual level.

\section{Statistical Analysis}

This study used SAS version 9.4 (SAS Institute Inc., Cary, NC, USA) for the statistical analysis. A descriptive analysis was performed and rate differences in outcomes were calculated. Multilevel logistic regression was performed to evaluate the effects of independent variables.

The regression equation of the multilevel analysis in this study is as follows:

$$
\begin{gathered}
\log \left[\frac{P\left(Y_{i j}=1\right)}{1-P\left(Y_{i j}=1\right)}\right]=\beta_{0 j}+\beta_{1 j} * X_{1 i j} \\
\beta_{0 j}=\gamma_{00}+\gamma_{01} * W_{j}+u_{0 j} \\
\beta_{1 j}=\gamma_{10}+\gamma_{11} * W_{j}
\end{gathered}
$$

$Y_{i j}$ : individual $\mathrm{i}$ in area $j$

$Y_{i j}=1$ : utilization of PHC / adequate treatment (HTN, DM) $\beta_{0 j}$ : mean log-odds of region $j$

$X_{1 i j}: j$ individual-level variables for region $i$ (sex, age, household income)

$\beta_{1 j}$ : slope of $X_{1 i j}$

$\gamma_{00}$ : intercept for $\beta_{0 j}$

$W_{j}$ : j regional-level variables (OOP exemption, elderly population ratio, number of $\mathrm{PHCs}$, ratio of other medical institutions)

$\gamma_{01}$ : slope of $W_{j}$ reaching $\beta_{0 j}$ prediction

$u_{0 j}$ : error term for $\beta_{0 j}$ in region $j$

$\gamma_{10}$ : intercept for $\beta_{1 j}$

$\gamma_{11}$ : slope of $W_{j}$ reaching $\beta_{1 j}$ prediction

This model involves 2-level multiple logistic regression analysis with a binary outcome. The model of this regression ignores the random slope effect since it is not logical to assume that individual-level variables would have different effects depending on the region. Instead, this model only assumes the 
random intercept effect. The final formula of the multilevel logistic regression was as follows:

$\log \left[\frac{P\left(Y_{i j}=1\right)}{1-P\left(Y_{i j}=1\right)}\right]=\gamma_{00}+u_{0 j}+\gamma_{01} * W_{j}+\gamma_{10} * X_{1 i j}+\gamma_{11} * W_{j} * X_{1 i j}$

The analysis consisted of 3 models. Model 1 was an empty model that only evaluated regional effects:

$$
\log \left[\frac{P\left(Y_{i j}=1\right)}{1-P\left(Y_{i j}=1\right)}\right]=\gamma_{00}+u_{0 j}
$$

The intraclass correlation coefficient (ICC) was calculated. Model 2 was an regression analysis with regional-level variables:

$$
\log \left[\frac{P\left(Y_{i j}=1\right)}{1-P\left(Y_{i j}=1\right)}\right]=\gamma_{00}+u_{0 j}+\gamma_{01} * W_{j}
$$

From the above equation, it was possible to investigate the degree to which the regional variables described the log-odds when individual variables were not considered.

Model 3 added individual-level variables, with the same equation as the overall regression equation presented above.

\section{Ethics Statement}

This study was approved by the Institutional Review Board (IRB) of Seoul National University (IRB No. E2004/002-003).

\section{RESULTS}

\section{Descriptive Analysis}

The current status of OOP exemption policies for the elderly in regions other than metropolitan cities in Korea is shown in Figure 2. Most of these regions have implemented these poli-

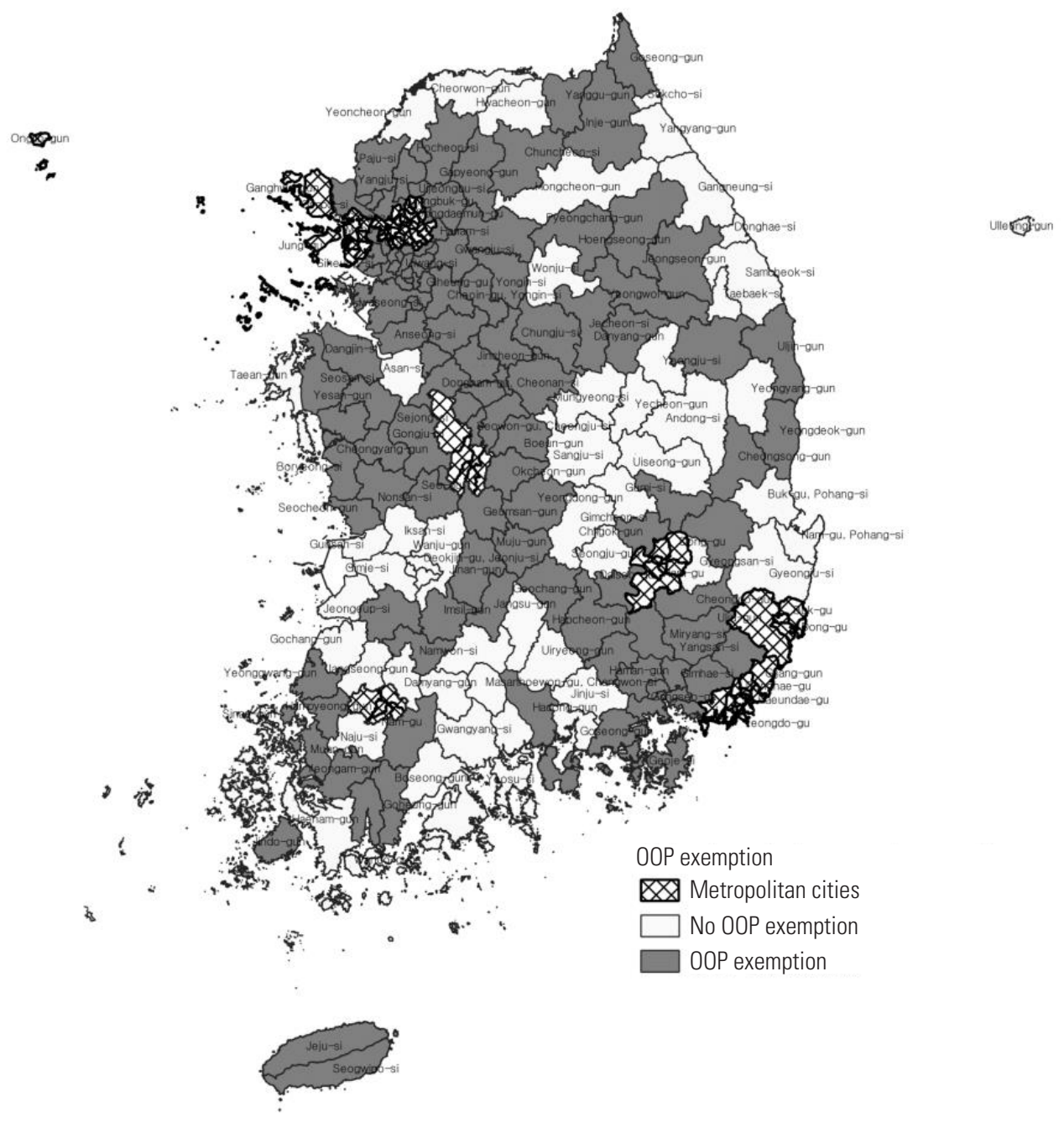

Figure 2. Out-of-pocket payment (OOP) exemption. 
cies for more than 10 years, since the early 2000s.

In Gyeonggi Province, 30 regions had exemptions and 1 region did not. In Gangwon Province, 8 regions had exemptions and 10 regions did not. In North Chungcheong Province (11 regions) and Jeju Province (2 regions), all regions had exemptions. In South Chungcheong Province, 12 regions had exemptions and 2 regions did not. In North Jeolla Province, 6 regions had exemptions and 8 regions did not. In South Jeolla Province, 9 regions had exemptions and 13 regions did not. In North Gyeongsang Province, 9 regions had exemptions and 14 regions did not. In South Gyeongsang Province, 14 regions had exemptions and 4 regions did not.

The ratio of other medical facilities to PHCs was calculated by dividing the number of other medical facilities, such as private hospitals, by the number of medical PHCs (PHCs with medical care function, where they have medical doctors, including health centers and health center branches). Figure 3 shows a map of these ratios. Most of the regions with high ratios (>30) were adjacent to or near metropolitan areas, and they comprised 19 cities (si) and 2 districts ( $g u$ ) in Gyeonggi Province, 5 cities and 7 districts in other regions, and no county (gun) regions.

A descriptive analysis of the respondents to the Community Health Survey is shown in Table 1.

There were, in total, 44918 respondents, of whom $59.2 \%$ were females. The age distribution (in terms of 5 -year intervals) was fairly even. The monthly household income was 500000 Korean won (KRW) or less for $15.4 \%$ of participants, $500000 \mathrm{KRW}$ to $1000000 \mathrm{KRW}$ for $31.6 \%, 1000000 \mathrm{KRW}$ to $2000000 \mathrm{KRW}$ for $27.6 \%, 2000000 \mathrm{KRW}$ to $3000000 \mathrm{KRW}$ for $12.0 \%$, and more than $3000000 \mathrm{KRW}$ for $13.4 \%$.

The PHC utilization rate was $71.1 \%$, and adequate treatment rates of HTN and DM were $91.2 \%$ and $83.4 \%$, respectively.

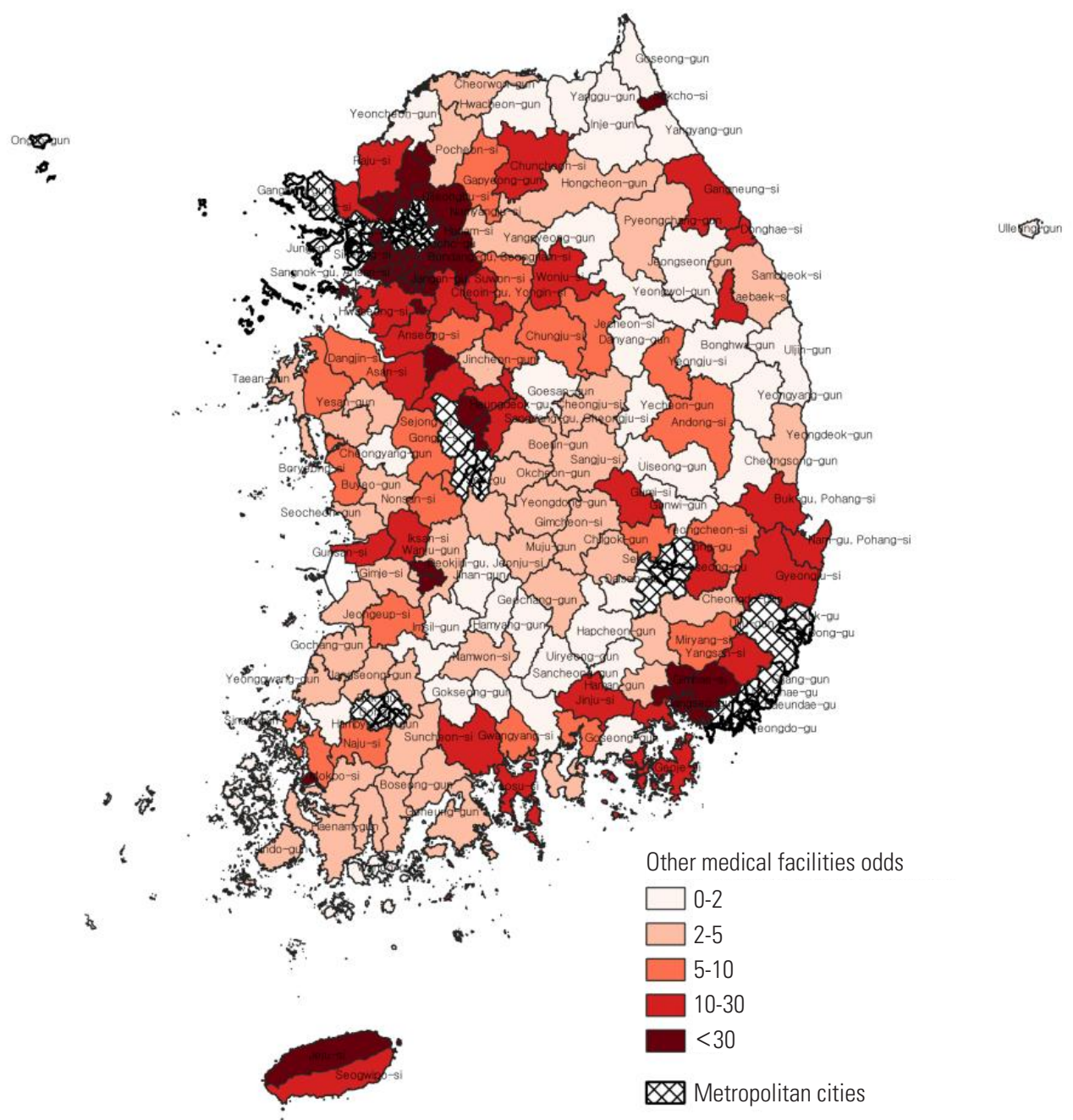

Figure 3. Odds of other medical facilities to medical public health centers. 
Table 1. Descriptive analysis of the participants

\begin{tabular}{|c|c|c|}
\hline Characteristics & Category & n (\%) \\
\hline \multirow[t]{2}{*}{ Sex } & Male & $18317(40.8)$ \\
\hline & Female & $26601(59.2)$ \\
\hline \multirow[t]{4}{*}{ Age (y) } & $65-69$ & $11446(25.5)$ \\
\hline & $70-74$ & $10656(23.7)$ \\
\hline & $75-79$ & 11634 (25.9) \\
\hline & $\geq 80$ & $11182(24.9)$ \\
\hline \multirow{6}{*}{$\begin{array}{l}\text { Monthly household income } \\
\text { (1000 Korean won) }\end{array}$} & $1:<500$ & $6687(15.4)$ \\
\hline & 2: $500-1000$ & $13712(31.6)$ \\
\hline & 3: $1000-2000$ & $12003(27.6)$ \\
\hline & 4: $2000-3000$ & $5192(12.0)$ \\
\hline & $5: \geq 3000$ & $5828(13.4)$ \\
\hline & Missing & 1496 \\
\hline \multirow[t]{9}{*}{ Area of residence } & Gyeonggi Province & $3057(6.8)$ \\
\hline & Gangwon Province & $5132(11.4)$ \\
\hline & Chungcheongbuk Province & $3471(7.7)$ \\
\hline & Chungcheongnam Province & $4782(10.6)$ \\
\hline & Jeollabuk Province & $5005(11.1)$ \\
\hline & Jeollanam Province & $8329(18.5)$ \\
\hline & Gyeongsangbuk Province & $8762(19.5)$ \\
\hline & Gyeongsangnam Province & $5584(12.4)$ \\
\hline & Jeju Province & $796(1.8)$ \\
\hline \multirow{3}{*}{$\begin{array}{l}\text { Public health center } \\
\text { utilization }\end{array}$} & 0 : No (in recent 1 y) & $12987(28.9)$ \\
\hline & 1: Yes (in recent $1 \mathrm{y}$ ) & $31922(71.1)$ \\
\hline & Missing & 9 \\
\hline \multirow[t]{3}{*}{ Hypertension treatment } & 0 : Inadequate & $2214(8.8)$ \\
\hline & 1: Adequate & 22994 (91.2) \\
\hline & Missing & 19710 \\
\hline \multirow[t]{3}{*}{ Diabetes mellitus treatment } & 0 : Inadequate & $1485(16.6)$ \\
\hline & 1: Adequate & $7434(83.4)$ \\
\hline & Missing & 35999 \\
\hline
\end{tabular}

\section{Rate Differences}

The weighted rate difference was calculated to compare the crude rates of the dependent variables between regions with OOP exemptions and the comparison regions without OOP exemptions (Table 2). In the OOP exemption regions, the PHC utilization rate was $62.0 \%$, while it was $60.0 \%$ in the comparison regions, reflecting a statistically significant rate difference of $1.97 \%$ p ( $95 \% \mathrm{Cl}, 1.07$ to 2.08$)$, which means that regions with OOP exemptions had a PHC utilization rate that was $1.97 \% \mathrm{p}$ higher than the comparison regions.

The treatment rate of HTN in the OOP exemption regions and the comparison regions was $91.8 \%$ and $90.5 \%$ respectively. The rate difference was $1.37 \% \mathrm{p}(95 \% \mathrm{Cl}, 0.67$ to 2.08$)$, which was statistically significant; thus, regions with OOP exemp- tions had $1.37 \%$ p higher rates of adequate HTN treatment than the comparison regions.

The treatment rate of DM in the OOP exemption regions and the comparison regions was $84.4 \%$ and $82.2 \%$, respectively. The rate difference was $2.19 \% \mathrm{p}(95 \% \mathrm{Cl}, 0.63$ to 3.74$)$, and was statistically significant, meaning that regions with OOP exemptions had 2.19\%p higher rates of adequate DM treatment than the comparison regions.

\section{Logistic Regression}

The results of the multilevel logistic regression analysis are shown in Table 2.

For PHC utilization, the ICC was calculated to be 0.146 , meaning that regional differences explained $14.6 \%$ of PHC utilization. In model 2, among region-level independent variables, the proportion of the elderly population, the number of PHCs, and the ratio of other medical facilities showed statistical significance, as well as in model 3. The individual-level independent variables all showed statistical significance. The OOP exemption showed no effect on PHC utilization, while a proportionally larger elderly population, a lower number of PHCs, and a lower ratio of other medical facilities had a positive effect on the utilization of PHCs. Female sex, older age, and lower household income were also associated with higher PHC utilization.

For the treatment of HTN, the ICC was 0.049 , meaning that $4.9 \%$ of variation in the treatment rate was explained by regional differences. Only the OOP exemption had a statistically significant effect on the HTN treatment rate at the regional level in model 2, as well as in model 3. The odds ratio was 1.21 $(95 \% \mathrm{Cl}, 1.02$ to 1.43$)$ in model 2 and $1.25(95 \% \mathrm{Cl}, 1.05$ to 1.48$)$ in model 3. The individual-level variables of age and household income showed statistical significance. Regions with the OOP exemption, a younger population, and a higher household income had higher rates of appropriate HTN treatment.

For DM treatment, the ICC was 0.046 , meaning that regional differences explained $4.6 \%$ of the DM treatment rate. In model 2 , among the region-level independent variables, the proportion of the elderly population and the ratio of other medical facilities showed statistical significance, as well as in model 3. As individual-level independent variables, age and household income showed statistical significance. Regions with a lower proportion of the elderly population, a lower ratio of other medical facilities, and individuals with a higher age and a generally higher household income showed higher rates of appropriate DM treatment. 
Table 2. Rate difference and regression analysis

\begin{tabular}{|c|c|c|c|}
\hline Variables & PHC utilization & HTN treatment & DM treatment \\
\hline \multicolumn{4}{|l|}{ Regions, weighted rate \% (95\% CI) } \\
\hline 0: No OOP exemption & $60.0(59.3,60.8)$ & $90.5(89.9,91.1)$ & $82.2(80.9,83.4)$ \\
\hline 1: 00P exemption & $62.0(61.4,62.6)$ & $91.8(91.4,92.3)$ & $84.4(83.4,85.4)$ \\
\hline Rate difference (1-0), \%p & $1.97(1.07,2.88)^{* * *}$ & $1.37(0.67,2.08)^{* * *}$ & $2.19(0.63,3.74)^{* *}$ \\
\hline \multicolumn{4}{|l|}{ Models, OR (95\% Cl) } \\
\hline \multicolumn{4}{|l|}{ Model 1} \\
\hline Intercept & $2.39(2.10,2.73)^{* * *}$ & $11.13(10.22,12.13)^{* * *}$ & $5.29(4.83,5.80)^{* * *}$ \\
\hline-2 log likelihood & 50522.43 & 14803.69 & 7957.86 \\
\hline ICC & $0.146^{* * *}$ & $0.049 * * *$ & $0.046^{* * *}$ \\
\hline \multicolumn{4}{|l|}{ Model 2} \\
\hline Intercept & $2.54(1.404 .63)^{* *}$ & $10.64(6.20,18.26)^{* * *}$ & $9.07(5.08,16.20)^{* * *}$ \\
\hline О०Р exemption & $0.96(0.79,1.16)$ & $1.21(1.02,1.43)^{*}$ & $1.00(0.83,1.20)$ \\
\hline Elderly proportion & $1.03(1.01,1.04)^{* *}$ & $0.99(0.98,1.01)$ & $0.98(0.96,1.00)^{*}$ \\
\hline No. of PHC & $0.99(0.98,1.00)^{*}$ & $1.00(0.99,1.01)$ & $1.00(0.99,1.02)$ \\
\hline Ratio of other medical facilities & $0.95(0.93,0.97)^{* * *}$ & $1.00(0.98,1.02)$ & $0.98(0.96,1.00)^{*}$ \\
\hline-2 log likelihood & 50440.69 & 14797.83 & 7951.58 \\
\hline \multicolumn{4}{|l|}{ Model 3} \\
\hline Intercept & $1.91(1.03,3.54)^{*}$ & $10.48(5.85,18.76)^{* * *}$ & $7.60(3.98,14.53)^{* * *}$ \\
\hline 00P exemption & $1.00(0.82,1.22)$ & $1.25(1.05,1.48)^{*}$ & $1.00(0.83,1.21)$ \\
\hline Elderly proportion & $1.03(1.01,1.04)^{* *}$ & $0.99(0.98,1.01)$ & $0.98(0.96,1.00)^{*}$ \\
\hline No. of PHCs & $0.99(0.98,1.00)^{*}$ & $1.00(0.99,1.01)$ & $1.01(1.00,1.02)$ \\
\hline Ratio of other medical $f$ acilities & $0.95(0.93,0.97)^{* * *}$ & $1.00(0.98,1.02)$ & $0.98(0.96,1.00)^{*}$ \\
\hline Sex (female) & $1.18(1.12,1.23)^{* * *}$ & $1.07(0.97,1.18)$ & $0.88(0.78,1.00)$ \\
\hline \multicolumn{4}{|l|}{ Age (y) } \\
\hline $65-69$ & 1.00 (reference) & 1.00 (reference) & 1.00 (reference) \\
\hline $70-74$ & $1.19(1.12,1.27)^{* * *}$ & $0.90(0.78,1.05)$ & $1.06(0.90,1.25)$ \\
\hline $75-79$ & $1.29(1.21,1.38)^{* * *}$ & $0.88(0.76,1.01)$ & $1.16(0.98,1.37)$ \\
\hline$\geq 80$ & $1.25(1.17,1.34)^{* * *}$ & $0.72(0.63,0.83)^{* * *}$ & $1.22(1.02,1.47)^{*}$ \\
\hline \multicolumn{4}{|l|}{ Income level } \\
\hline 1 & 1.00 (reference) & 1.00 (reference) & 1.00 (reference) \\
\hline 2 & $1.07(0.99,1.14)$ & $1.03(0.90,1.17)$ & $1.01(0.84,1.20)$ \\
\hline 3 & $0.97(0.90,1.05)$ & $1.06(0.92,1.23)$ & $1.20(0.99,1.45)$ \\
\hline 4 & $0.92(0.84,1.01)$ & $1.29(1.07,1.56)^{* *}$ & $1.58(1.24,2.01)^{* * *}$ \\
\hline 5 & $0.81(0.73,0.89)^{* * *}$ & $1.43(1.14,1.80)^{* *}$ & $1.28(0.97,1.69)$ \\
\hline-2 log likelihood & 45416.60 & 13537.34 & 7253.99 \\
\hline
\end{tabular}

PHC, public health center; HTN, hypertension; DM, diabetes mellitus; $\mathrm{Cl}$, confidence interval; OR, odds ratio; OOP, out-of-pocket payment. ${ }^{*} p<0.05,{ }^{* *} p<0.01,{ }^{* * *} p<0.001$.

\section{DISCUSSION}

This study summarized OOP exemption policies for the elderly across non-metropolitan regions in Korea for the first time, and showed that the lack of such a policy can hinder HTN treatment. Additionally, the effects of the relatively small amount of OOPs were analyzed quantitatively from the perspective of medical utilization.
Without adjustment, PHC utilization, HTN treatment, and DM treatment showed significant rate differences between regions with OOP exemption policies and those without OOP exemption policies. The multilevel logistic regression found that the presence of an exemption policy only had a significant effect on HTN treatment. Other regional factors, such as the number of PHCs, the ratio of other medical facilities, and the proportion of the elderly population, showed some effects 
on the outcomes, and individual factors such as sex, age, and household income showed some effects as well.

The geographical distribution of OOP exemption policies was found to be relatively homogeneous in Gyeonggi Province, South Chungcheong Province, North Chungcheong Province, and Jeju Province. Policy diffusion, demographic factors, and the distribution of medical facilities may have affected the spatial correlation of these policies. In the Korean context, the presence of high elderly population and rural areas in a region can affect the tax income of the local government, which may have affected the likelihood of implementing an exemption policy to reduce medical expenditures.

OOPs are defined as direct payments made by individuals to healthcare providers at the time of service use [10]. In Anderson's healthcare utilization model, OOPs are a factor associated with individuals' access to medical services $[11,12]$. However, it should be kept in mind that there are many non-financial factors that may also have affected medical utilization.

Nonetheless, several previous studies have found an association between high OOPs and reduced medical utilization $[6,13,14]$. Studies of OOPs in the Korean healthcare system also showed similar findings $[15,16]$. According to a recent study from the World Health Organization, OOPs (or copayments) may account for a large proportion of health financing, especially in countries with low public spending on health, but are not an effective rationing instrument due to strong and consistent evidence that they reduce necessary and unnecessary use in equal measure [17]. Regarding the treatment of chronic diseases, a systematic review showed that higher patient shares of medication costs were significantly associated with lower adherence [18], which implies that the treatment rate is associated with OOPs. The results of this study, therefore, showed partial concordance with previous studies.

Regarding PHC utilization, the rate difference was 1.97\%p, whereas the regression analysis did not show a significant effect. One possible reason could be due to the questionnaire used to measure PHC utilization, which included any form of utilization of a PHC in the recent 1 year. PHCs provide free vaccinations and other free services, such as physiotherapy, acupuncture for smoking cessation, sports programs, dementia screening, and medical visits depending on the community and the local governments. The outcome of PHC utilization included all of these services; as such, it was not a fully representative outcome variable of medical utilization only.

The HTN and DM treatment rates were both higher in re- gions with the OOP exemption (rate difference, 1.37\%p and $2.19 \%$ p respectively). In the logistic regression analysis, however, only HTN treatment showed a statistically significant effect from OOP exemptions. Unlike PHC utilization, the variables of HTN and DM treatment may reflect medical utilization more closely. However, the OOP exemption only had a statistically significant effect on HTN treatment. There could be many reasons why the effect on DM treatment was insignificant. A possible reason may be the different traits of DM and HTN treatment. Compared to HTN, DM treatment requires more invasive methods for follow-up, and indicators such as blood sugar levels fluctuate widely depending on dietary habits, physical status, and environmental factors. Insulin injections may also be needed, which are invasive and more complicated than taking drugs. These factors may explain why the treatment rate for DM was lower than the HTN treatment rate.

The limitations of this study are as follows.

Firstly, the data were limited to 2018, making this a crosssectional study. Reverse causality is always possible, even though this policy has been implemented for a fairly long time.

Secondly, there is an issue regarding comparability (or exchangeability). The subjects from regions with and without OOP exemption policies should have homogeneous traits except for the variables of our interest, but it is difficult to ensure that the subjects had similar access to PHCs, political ideas, and cultural characteristics, since the subjects were not randomized.

Thirdly, not all expenditures for medical utilization were considered. Depending on where the elderly live, there may be variations in coverage. For instance, PHCs may offer drugs free of charge in some regions due to a lack of pharmacies, while that may not be the case in other regions. The local laws themselves are not binary and differences exist in the items that are covered. Additionally, some regions have financial support programs, such as the Hypertension/Diabetes Registration Management Program by the Korean Centers for Disease Control and Prevention, which was not considered in the analysis. Previous studies have also shown that even OOPs are covered, patients had to incur substantial costs to use free services in addition to travel costs [19].

Lastly, PHC utilization has limitations as a measure of medical utilization of PHCs due to the questionnaire-related problem stated above.

Despite its limitations, this study has reliability since it ana- 
lyzed data from a large sample population. It should be noted that OOP exemptions had positive effects on HTN treatment, which supports further initiatives to expand the OOP exemption policy, even though the OOPs are relatively small when using PHCs. Through redistribution of wealth and improvements in coverage and accessibility, expanding the OOP exemption policy may have positive effects on health outcomes by improving the adequacy of HTN treatment, especially for elderly individuals in rural areas.

\section{CONFLICT OF INTEREST}

The authors have no conflicts of interest associated with the material presented in this paper.

\section{FUNDING}

None.

\section{ACKNOWLEDGEMENTS}

This paper is based on "Effects of out-of-pocket payment exemption in local public health center among Korean elderly in association with medical utilization and unmet medical need," the lead author's master's thesis at the Graduate School of Public Health, Seoul National University.

\section{AUTHOR CONTRIBUTIONS}

Conceptualization: KN. Data curation: KN. Formal analysis: KN, EP. Funding acquisition: None. Methodology: KN, EP, CYK. Writing - original draft: KN. Writing - review \& editing: KN, EP, YC, CYK.

\section{ORCID}

Kiryong Nam https://orcid.org/0000-0002-4253-6335

Eunhye Park https://orcid.org/0000-0003-3357-8522

Yuhjin Chung https://orcid.org/0000-0001-9184-5612

Chang-yup Kim https://orcid.org/0000-0002-4389-2454

\section{REFERENCES}

1. Beck RG. The effects of co-payment on the poor. J Hum Resour 1974;9(1):129-142.
2. Ha MJ, Seo I, Kwon GH. Local government's policy actors and policy diffusion in Korea. Korean Public Adm Rev 2011;45(4): 151-179 (Korean).

3. Yoo H, Lah TJ. A study on the influencing factors of establishment of conflict related ordinance of local government: focusing on the isomorphism theory of new institutionalism. Korean J Local Gov Stud 2019;23(2):47-70 (Korean).

4. Bae SS. An empirical test on the policy diffusion of childbirth grant adoption: focused on local governments in the capital region. Korean Policy Stud Rev 2010;19(4):273-298 (Korean).

5. Choi S. The diffusion and factors of the civil participatory budget system in local government. Korean Public Adm Rev 2010; 44(3):87-113 (Korean).

6. Rice T, Matsuoka KY. The impact of cost-sharing on appropriate utilization and health status: a review of the literature on seniors. Med Care Res Rev 2004;61(4):415-452.

7. Qin VM, Hone T, Millett C, Moreno-Serra R, McPake B, Atun R, et al. The impact of user charges on health outcomes in lowincome and middle-income countries: a systematic review. BMJ Glob Health 2019;3(Suppl 3):e001087.

8. Park EA, Choi SY. Analysis of factors influencing the utilization rate of public health centers in Korea. J Korea Acad Ind Coop Soc 2019;20(3):2013-215 (Korean).

9. Suttorp MM, Siegerink B, Jager KJ, Zoccali C, Dekker FW. Graphical presentation of confounding in directed acyclic graphs. Nephrol Dial Transplant 2015;30(9):1418-1423.

10. World Health Organization. Out-of-pocket payments, user fees and catastrophic expenditure [cited 2020 Sep 10]. Available from: https://www.who.int/health_financing/topics/financialprotection/out-of-pocket-payments/en/.

11. Andersen R, Newman JF. Societal and individual determinants of medical care utilization in the United States. Milbank Mem Fund Q Health Soc 1973;51(1):95-124.

12. Andersen RM, Davidson PL, Baumeister SE. Improving access to care. In: Kominski GF, editor. Changing the U.S. health care system: key issues in health services policy and management, 4th ed. San Francisco: Jossey-Bass; 2013, p. 33-69.

13. Qingyue M, Liying J, Beibei Y. Cost-sharing mechanisms in health insurance schemes: a systematic review; 2011 [cited 2020 Oct 20]. Available from: http://www.who.int/alliancehpsr/projects/alliancehpsr_chinasystematicreviewcostsharing.pdf.

14. Gruber J, Maclean JC, Wright BJ, Wilkinson ES, Volpp K. The impact of increased cost-sharing on utilization of low value services: evidence from the State of Oregon (No. w22875); 
2016 [cited 2020 Oct 20]. Available from: https://www.nber. org/system/files/working_papers/w22875/w22875.pdf.

15. Hong SW. The effects of copayments on health services utilization in the type i medicaid beneficiaries. J Korean Acad Nurs Adm 2009;15(1):136-146 (Korean).

16. Kim M, Kwon S. The effect of outpatient cost sharing on health care utilization of the elderly. J Prev Med Public Health 2010; 43(6):496-504 (Korean).
17. Thomson S, Cylus J, Evetovits T. Can people afford to pay for health care? New evidence on financial protection in Europe. Eurohealth 2019;25(3):41-46.

18. Eaddy MT, Cook CL, O'Day K, Burch SP, Cantrell CR. How patient cost-sharing trends affect adherence and outcomes: a literature review. PT 2012;37(1):45-55.

19. Abel-Smith B, Rawal P. Can the poor afford 'free'health services? A case study of Tanzania. Health Policy Plan 1992;7(4):329-341. 